\title{
Speed control strategy for tractor assisted driving based on chassis dynamometer test
}

\author{
Xiaorui Zhang ${ }^{1}$, Zhili Zhou ${ }^{2 *}$ \\ (1. School of Mechanical and Precision Instrument Engineering, Xi' an University of Technology, Xi'an 710048, China; \\ 2. School of Vehicle and Traffic Engineering School, Henan University of Science and Technology, Luoyang 471003, China)
}

\begin{abstract}
Realizing automation of the chassis dynamometer and the unmanned test workshop is an inevitable trend in the development of new tractor products. The accuracy of the speed control of the test tractor directly affects the accuracy of the test loading force. In order to meet the purpose of precise control of the test tractor speed on the chassis dynamometer, a fuzzy PID control strategy was developed according to the working principle of assisted driving. On the basis of traditional PID control, the parameters of fuzzy inference module were added for real-time adjustment to achieve faster response to tractor speed changes and more precise control of tractor speed. The Matlab-Cruise co-simulation platform was established for simulation, and the experiment was verified by the tractor chassis dynamometer using the NEDC working condition and tractor ploughing working condition. The results show that both PID control and fuzzy PID control can achieve tractor speed following accuracy of $\pm 0.5 \mathrm{~km} / \mathrm{h}$. Fuzzy PID control has higher tractor speed following accuracy, faster response when speed changes, less tractor speed fluctuation, and overall control effect is better than PID control. The research results can provide a reference for the realization of the chassis dynamometer unmanned test workshop.
\end{abstract}

Keywords: tractor, chassis dynamometer, assisted driving, speed control, fuzzy PID

DOI: $10.25165 /$ j.ijabe.20211406.6380

Citation: Zhang X R, Zhou Z L. Speed control strategy for tractor assisted driving based on chassis dynamometer test. Int J Agric \& Biol Eng, 2021; 14(6): 169-175.

\section{Introduction}

Tractor is an important part of agricultural machinery and power equipment for agricultural production. With the goal of smart agriculture and precision agriculture, new tractor products are developing towards modern operation methods featuring high power, high speed, low consumption, intelligence and high efficiency ${ }^{[1-3]}$. As one of the important technologies for advanced product development, test verification runs through the entire life cycle of product demand analysis, design, development, and use ${ }^{[4]}$. The tractor test standard requires that the tractor endurance test on the chassis dynamometer should not be less than $160000 \mathrm{~km}^{[5]}$. The accuracy of the chassis dynamometer test results depends to a large extent on the driver's driving level, response ability and work attitude $^{[6-8]}$. By integrating the assisted driving device into the chassis dynamometer control system, the test tractor and the test system form a closed loop, which completely replaces the driver to control the tractor and carry out the test on the chassis dynamometer according to the preset test procedure. This can not only reduce the driver's work intensity, reduce test costs, and improve test efficiency, but also eliminate the driver's intervention in the test process, and make the response of the chassis dynamometer more scientific and accurate ${ }^{[9,10]}$.

In order to improve the automation level of the chassis dynamometer and realize the unmanned test workshop, assisted driving devices have been studied by many local and international

Received date: 2020-12-26 Accepted date: 2021-09-11

Biographies: Xiaorui Zhang, $\mathrm{PhD}$ post-graduate, research interests: vehicle test technology and equipment, Email: zhangxiaorui152@163.com.

*Corresponding author: Zhili Zhou, PhD, Professor, research interests: new transmission theory and control technology of vehicles, School of Vehicle and Traffic Engineering, Henan University of Science and Technology, Luoyang 471003, China. Tel: +86-13937912290, Email: zzli@haust.edu.cn. researchers. Zhang et al. ${ }^{[11-13]}$ designed assisted driving devices for automobile chassis dynamometer tests, which avoided the influence of drivers on the test and improved the repeatability of automobile performance tests. Nikolaus et al. ${ }^{[14]}$ proposed a nonlinear decoupling multiple control scheme based on feedback linearization, which realized the automatic continuous test of the vehicle chassis dynamometer. The research of tractor-assisted driving device started later than vehicle. Foreign countries were represented by the tractor-assisted driving device developed by ATC in Minnesota, USA, which realized fully intelligent autonomous navigation operations, but the technology of tractor-assisted driving device was complicated and costly ${ }^{[15-17]}$. Only Nanjing University of Agricultural in China had developed a tractor-assisted driving device, which was a pure electric drive actuator and could realize transportation, ploughing and rotary tillage operations ${ }^{[18-20]}$. However, for the assisted driving device used for the tractor chassis dynamometer test, the precise control of the tractor speed is the prerequisite to ensure the test accuracy. Due to the variety of tractor farmland operations and the large speed fluctuations, it is urgent to study the assisted driving control strategy to realize the precise tracking control of tractor speed to working conditions.

Aiming at the assisted driving control system for the chassis dynamometer of the automatic transmission tractor to meet its tractor speed control performance requirements, a fuzzy PID control strategy is developed to achieve precise control of tractor speed and rapid response to tractor speed changes. A Matlab-Cruise joint simulation platform is established, and NEDC working condition and ploughing working condition are used for simulation and tractor chassis dynamometer test verification to achieve the expected tractor speed control target, to lay the technical foundation for realizing the unmanned tractor chassis dynamometer test workshop. 


\section{Assisted driving speed control performance requirements}

The assisted driving control system is used to replace the driver to drive the tractor on the chassis dynamometer for the standard working condition tests. The most basic function is to realize the tracking control of the tractor speed. It should meet the following basic requirements:

(1) Tracking control of tractor speed. The tractor speed tracking control error should not exceed $1 \mathrm{~km} / \mathrm{h}$ during starting, accelerating, decelerating and constant speed and other working conditions,

(2) The control system is integrated into the chassis dynamometer system. The test cycle specified in the test standard is preset, and other test cycles can also be easily customized on the self-programming platform. It has the ability of compensation and fault tolerance for the performance changes of the test tractor caused by the long-term test.

(3) Self-learning ability. It should have the ability to self-learning the motion characteristics of each station of tractors in different operations, such as accelerator pedal stroke, brake pedal stroke, and transmission shift position, etc. It can automatically determine the relationship between the accelerator pedal displacement and engine speed, acceleration, tractor speed, and the relationship between brake pedal displacement and deceleration. At the same time, it should have the ability of compensation and fault tolerance for the performance changes of the tractor caused by the long-term test.

(4) Humanized driving characteristics. According to the driver's operating experience, the tractor's starting characteristics, braking characteristics, rapid acceleration, rapid deceleration and other characteristics are optimized to make the automatic driving more humanized. The operation should have some coordination and flexibility of human beings.

\section{Working principle and working process of assisted driving control system}

\subsection{Working principle of assisted driving control system}

For automatic transmission tractors, the assisted driving control system is mainly composed of the main control unit, data acquisition unit and actuator unit. Its working principle is shown in Figure 1.

(1) Main control unit. The main control unit receives sensor information collected by the data acquisition unit firstly. Combining the test tractor speed, engine speed and test tractor parameters provided by the chassis dynamometer system, the execution command signal is calculated and timely output by comparing the input data with the test driving condition data pre-input to the memory. The actuator unit is controlled by the servo control system to track the speed of the test tractor at last.

(2) Data acquisition unit. The data acquisition unit mainly collects the control force, displacement, speed and other information of the shift lever, brake pedal and accelerator pedal through the position sensor and feeds them back to the main control unit to ensure that the driving actions of the assisted driving control are accurate.

(3) Actuator unit. The actuator unit is mainly composed of accelerator mechanical leg, brake mechanical leg and shift manipulator. The accelerator and brake mechanical legs use a four-link mechanism instead of the driver to control the actions of the accelerator pedal and brake pedal to make the tractor speed up to the predetermined operating speed. The shift manipulator can select the matching gear to complete the automatic gear shift according to the actual tractor speed needs.

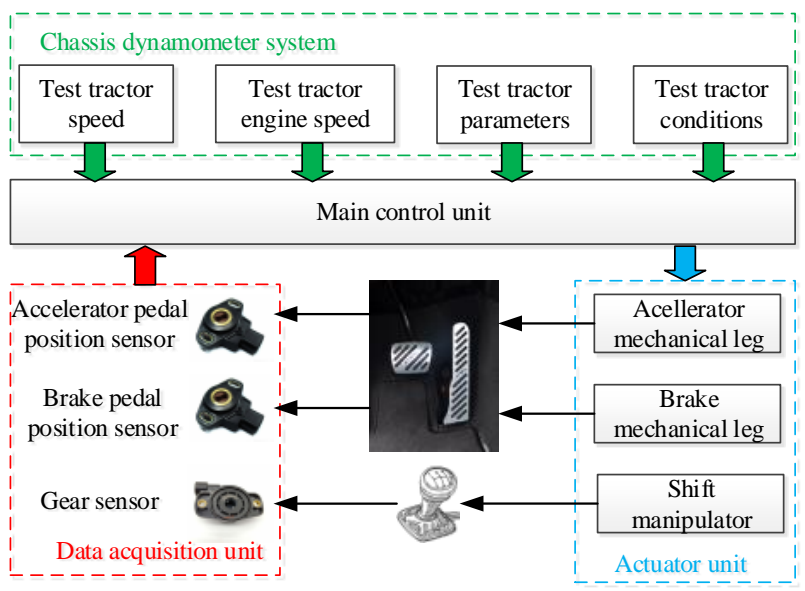

Figure 1 Schematic diagram of assisted driving control system

The mechanical leg actuator is controlled by the main control unit output signal through the servo control unit to control the stepper motor. The stepper motor drives the pedal actuator through the reducer. The actuator drives the pedal to change the speed of the tractor. The main control unit controls the pulse frequency through D/A, and then controls the motor speed. The steering of the motor is controlled by I/O. The rotation angle of the active lever is detected by the rotation angle sensor and fed back to the main control unit via A/D to achieve precise control of the pedal, the pedal control principle diagram is shown in Figure 2.

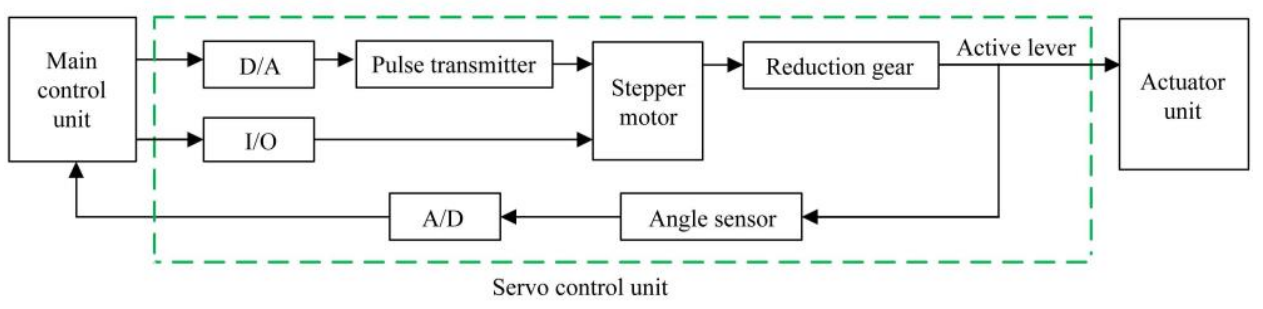

Figure 2 Pedal control principle diagram

\subsection{Working process of assisted driving control system}

Firstly, the actuator assembly of the assisted driving control system is connected with the tractor pedal and gear lever, and the relevant parameters are set by the operator. When the chassis dynamometer system is working, the actuator is controlled by the assisted driving control system to accelerate and decelerate the tractor according to the test driving conditions. During the test, the speed and other information of the tractor are continuously collected by the chassis dynamometer measurement and control system, and are compared with the test condition data to determine whether to accelerate or decelerate.

If the instantaneous speed of the tractor is lower than the speed required by the working condition, the tractor needs to accelerate, and the meter is quickly checked to obtain the required accelerator 
pedal displacement. After comparing with the accelerator pedal position information obtained by the data acquisition unit, the control signal is sent by the main control unit. The accelerator pedal is controlled by the servo control unit to accelerate the tractor. Otherwise, the brake pedal is controlled to decelerate.

\section{Tractor speed control strategy of assisted driving control system}

In order to achieve precise control of the tractor speed during the chassis dynamometer test, it is necessary to combine the accelerator pedal and the brake pedal for coordinated control.

PID control is simple, stable, reliable and can achieve more accurate control for most situations. However, the selection of proportional, integral and differential parameters needs to be determined by trial and error based on experience. If the selection is improper, it may cause problems of poor control accuracy and slow response. Fuzzy control has the advantages of being able to adapt to the nonlinearity and time-varying nature of the controlled object, and has good robustness. But its steady-state control accuracy is poor, and the control is not delicate. Therefore, the combination of fuzzy control and PID control can eliminate static errors and achieve higher control accuracy ${ }^{[21-22]}$. At the same time, it can respond faster to achieve better tractor speed tracking effect when the tractor speed changes suddenly.

In this study, a fuzzy PID controller was designed to control the accelerator pedal and the brake pedal, and the output value range of the controller is $[-1,1]$. When the output value is $[0,1]$, the accelerator pedal is selected for control, when the output value is $[-1,0]$, the brake pedal is selected for control. The principle of fuzzy PID controller is shown in Figure 3.

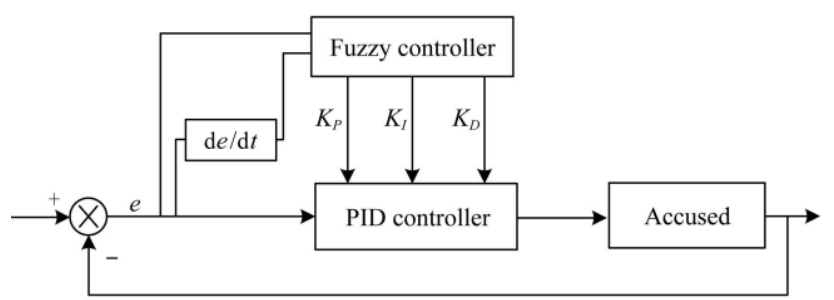

Figure 3 Fuzzy PID controller schematic diagram

\subsection{PID controller design}

The conventional PID controller has the characteristics of simple algorithm, good stability and high reliability. In addition, it is easy to design and has wide adaptability, making it the most widely used type of basic controller in process control. In this paper, PID controller is the basic controller, the output of PID controller is $u(t)$, and the input is $e(t)$. The relationship between them is,

$$
u(t)=K_{P} e(t)+K_{I} \int_{0}^{t} e(t) \mathrm{d} t+K_{D} \frac{\mathrm{d} e(t)}{\mathrm{d} t}
$$

where, $K_{P}$ is the proportional integral; $K_{I}$ is the integral gain, and $K_{D}$ is the differential gain.

\subsection{Fuzzy controller design}

In PID control, in order to obtain satisfactory control effect, it is necessary to adjust the three parameters of $K_{P}, K_{I}$ and $K_{D}$ in time according to the system status. Knowing the mathematical model of the controlled object, this task is often accomplished through online identification methods. But for systems with variable disturbances and erratic load changes, it is difficult to use online identification methods to adjust in real time. It is convenient and feasible to use fuzzy controllers to adjust these three parameters. A Mamdani fuzzy controller was used in this study, and the deviation $e(t)$ between the target tractor speed and the actual tractor speed and its change rate $\mathrm{d} e(t) / \mathrm{d} t$ is taken as the input of the fuzzy controller. The fuzzy variables $e$ and $e c$ can be obtained through the fuzzification of the input. Fuzzy decision is made according to fuzzy rules, and fuzzy control variables $U_{1}, U_{2}, U_{3}$ are obtained. After defuzzification and proportional transformation, the actual control output $K_{P}, K_{I}$ and $K_{D}$ are obtained. The parameters adjusted by the fuzzy controller are used in the PID control system to achieve the purpose of real-time adjustment of $K_{P}, K_{I}$ and $K_{D}$ with system changes.

\subsubsection{Establishment of membership function}

The fuzzy control membership function is formulated according to the following method: $e$ is quantized and calibrated to the interval $[-3,3]$, and the language value of the fuzzy subset is $\{\mathrm{NB}, \mathrm{NM}, \mathrm{NS}, \mathrm{ZO}, \mathrm{PS}, \mathrm{PM}, \mathrm{PB}\}$. After quantification of $e c$, it is calibrated to interval $[-3,3]$. The language value of the fuzzy subset is $\{\mathrm{NB}, \mathrm{NM}, \mathrm{NS}, \mathrm{ZO}, \mathrm{PS}, \mathrm{PM}, \mathrm{PB}\} . U_{1}, U_{2}, U_{3}$ are quantized and calibrated to the interval $[-3,3]$. The language value of the fuzzy subset is $\{\mathrm{ZO}, \mathrm{PS}, \mathrm{PM}, \mathrm{PB}\}$. The commonly used triangular membership function is selected. The membership function is shown in Figure 4.
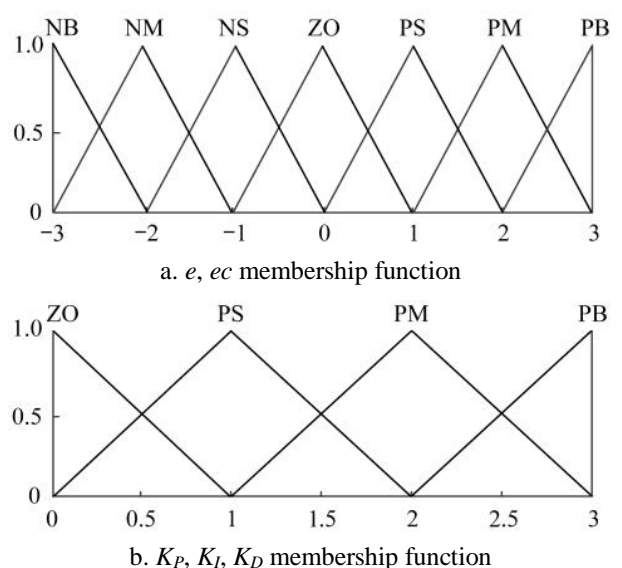

Figure 4 Membership function

\subsubsection{Establishment of fuzzy rules}

By summary of experience through many tests, and combining theoretical analysis, it can be concluded that there are following relationships during the deviation $e$, its change rate $e c$ and the three parameters $K_{P}, K_{I}$, and $K_{D}$ of the PID regulator:

(1) When $|e(t)|$ is larger, in order to speed up the response speed of the system, a larger $K_{P}$ should be used. In this way, the time constant and damping coefficient of the system can be reduced Of course, it should not be too large, otherwise the system will be unstable. In order to avoid the over-range control effect that the system may cause at the beginning, a smaller $K_{D}$ should be used to speed up system response. In order to avoid large overshoot, the integral effect can be removed, $K_{I}=0$.

(2) When $|e(t)|$ is at a medium size, the smaller $K_{P}$ should be used. A smaller $K_{P}$ should be used to make the overshoot of the system response slightly smaller. At this time, the value of $K_{D}$ is more critical to the system. To ensure the response speed of the system, the value of $K_{D}$ must be appropriate. At this time, a little $K_{I}$ can be appropriately increased, but not too large.

(3) When $|e(t)|$ is small, in order to make the system have good steady-state performance, larger $K_{P}$ and $K_{I}$ can be used. To avoid the system being justified at the equilibrium point, the value of $K_{D}$ should be appropriate.

Based on the qualitative relationship between the input variable $e$ and the three parameters $K_{P}, K_{I}, K_{D}$ summarized above, 
combining experience and considering the influence of the change rate of deviation $|e c(t)|$, the fuzzy rules for adjusting the three parameters of $K_{P}, K_{I}$ and $K_{D}$ are comprehensively obtained. The fuzzy regular surface diagram is shown in Figure 5.

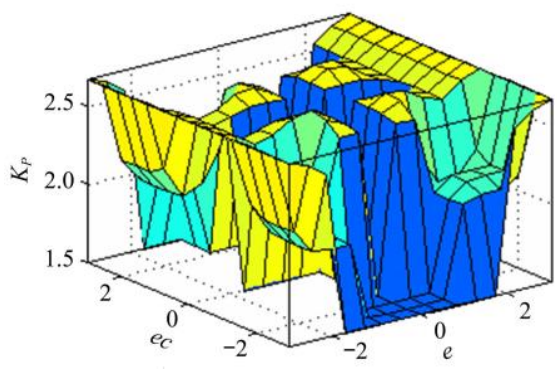

a. $K_{P}$ fuzzy regular

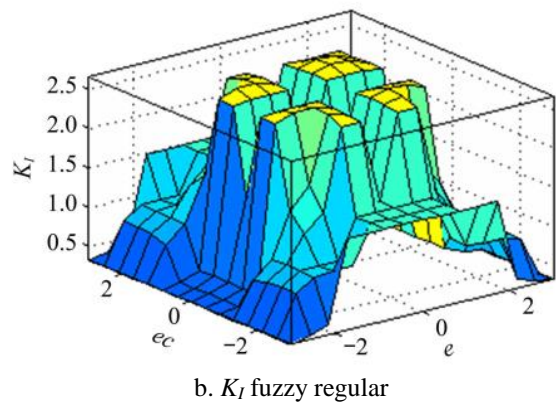

b. $K_{I}$ fuzzy regular

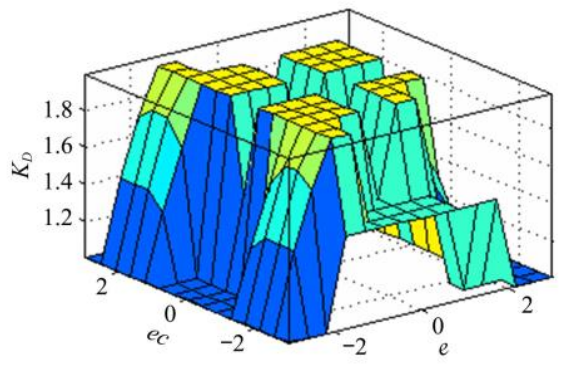

c. $K_{D}$ fuzzy regular

Figure 5 Fuzzy regular surface

\section{Tractor speed control strategy verification}

\subsection{Simulation verification}

The YTO MK-700 tractor is taken as the control object in this paper. The fuzzy PID control strategy model and the tractor model are established in Simulink and Cruise respectively, and the simulation results are analyzed through interface co-simulation. The main parameters of the tractor are shown in Table 1, and the joint simulation model and signal connection are shown in Figure 6.

In order to quantify the tractor speed following, $S$ is defined as the following tractor speed error ${ }^{[23]}$. The smaller the value, the better the tractor speed following and the closer to the target tractor speed. The tractor speed error can be expressed as:

$$
S=\int_{0}^{t}|e(t)| d t
$$

where, $t$ is the running time of the tractor, and $e(t)$ is the difference between the target speed and the actual speed.

Table 1 Parameters of the tractor

\begin{tabular}{lc}
\hline \multicolumn{1}{c}{ Parameter } & Value \\
\hline Minimum use weight/kg & 2700 \\
Maximum weight of front $/ \mathrm{rear} / \mathrm{kg}$ & $80 / 300$ \\
Engine model & Dongchai 4108 (self-priming) \\
Engine rated power/kW & 51.5 \\
Engine rated speed $/ \mathrm{r} \cdot \mathrm{min}^{-1}$ & 2200 \\
Gearbox number & $10+2$ \\
Speed range/km· $\mathrm{h}^{-1}$ & $0-42$ \\
Maximum power of PTO shaft/kW & 46.3 \\
Maximum traction $/ \mathrm{kN}$ & 15.5 \\
\hline
\end{tabular}

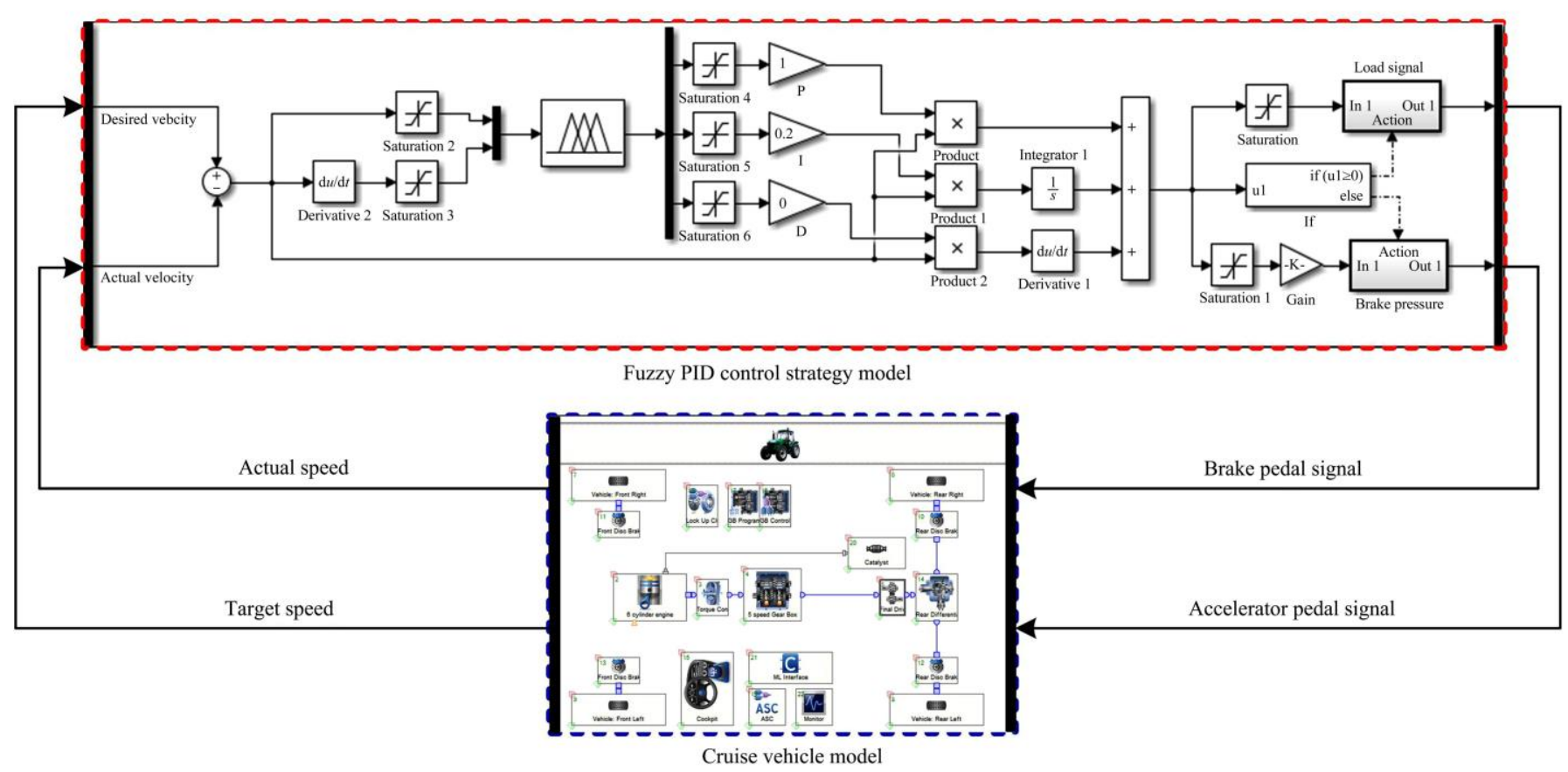

Figure 6 Cruise and Simulink joint simulation model and signal connection

The NEDC working condition and the actual measured tractor plowing working condition in 0-200 s are used as simulation condition, and PID control and fuzzy PID control are used to simulate respectively. The tractor speed following conditions and the results of following tractor speed error are shown in Figures 7 and 8.

It can be seen from Figure 7a and Figure 8a that under PID control and fuzzy PID control, the actual speed of the tractor can roughly follow the target speed, and the error between the following tractor speed and the target speed is within $\pm 0.5 \mathrm{~km} / \mathrm{h}$.
However, in the acceleration phase, when the PID control is used, since the values of $K_{P}, K_{I}$ and $K_{D}$ are fixed, the parameters cannot be adjusted quickly according to the actual situation when the target speed changes suddenly, resulting in large overshoot fluctuations in the actual tractor speed. In fuzzy PID control, when the target speed has a sudden change, the fuzzy control system will adjust the values of $K_{P}, K_{I}$, and $K_{D}$ according to the input $e(t)$ and $e c(t)$ to adapt to the tractor speed change, and the results show that when the tractor speed changes suddenly, the 
overshoot is greatly reduced, and the tractor speed quickly stabilizes. Compared with PID control, fuzzy PID control can respond faster when the tractor speed changes suddenly, and the tractor speed tracking effect is better.

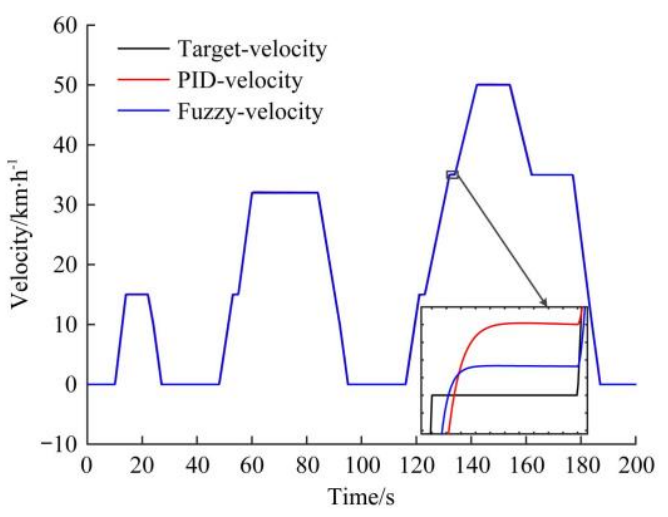

a. Speed following situation

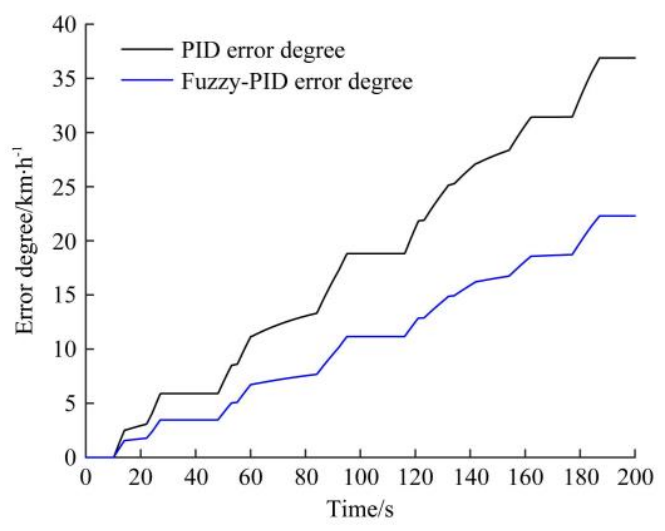

b. Error of following tractor speed

Figure 7 NEDC working condition

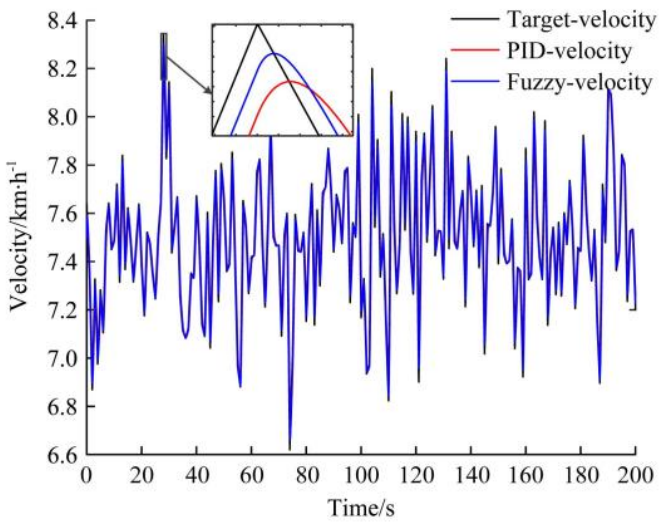

a. Speed following situation

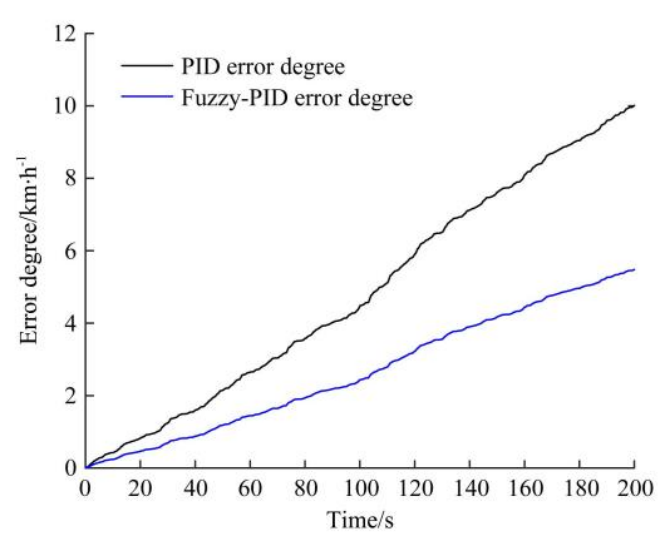

b. Error of following tractor speed

Figure 8 Plowing working condition
It can be seen from Figures $7 b$ and $8 b$ that the error of the tractor following the target speed under the fuzzy PID control is significantly smaller than that of the PID control. This shows that the fuzzy PID control make tractor speed following accuracy higher than PID control under complicated conditions such as acceleration, deceleration and ploughing.

According to the simulation results, whether in NEDC or plowing conditions, the fuzzy PID control strategy proposed in this study can make the tractor speed following effect better than the ordinary PID control strategy, and the error index is also the same, which verifies the superiority of the proposed control strategy.

\subsection{Test verification}

In order to further verify the effectiveness of the fuzzy PID control on the tractor speed control strategy of the assisted driving device, the YTO MK-700 tractor is used to be tested on the chassis dynamometer test bench in this paper. The main parameters of the chassis dynamometer are shown in Table 2 and the test site is shown in Figure 9.

Table 2 Chassis dynamometer parameters

\begin{tabular}{lc}
\hline \multicolumn{1}{c}{ Parameter } & Value \\
\hline Roller diameter/mm & 1700 \\
Distance between inner/outer edge of drum $/ \mathrm{mm}$ & $400 / 3000$ \\
Maximum allowable axle load/kg & 7000 \\
Maximum test speed $/ \mathrm{km} \cdot \mathrm{h}^{-1}$ & 120 \\
Load motor power $/ \mathrm{kW}$ & 132 \\
Load motor rated torque $/ \mathrm{N} \cdot \mathrm{m}$ & 840 \\
Maximum traction $/ \mathrm{kN}$ & 42 \\
\hline
\end{tabular}

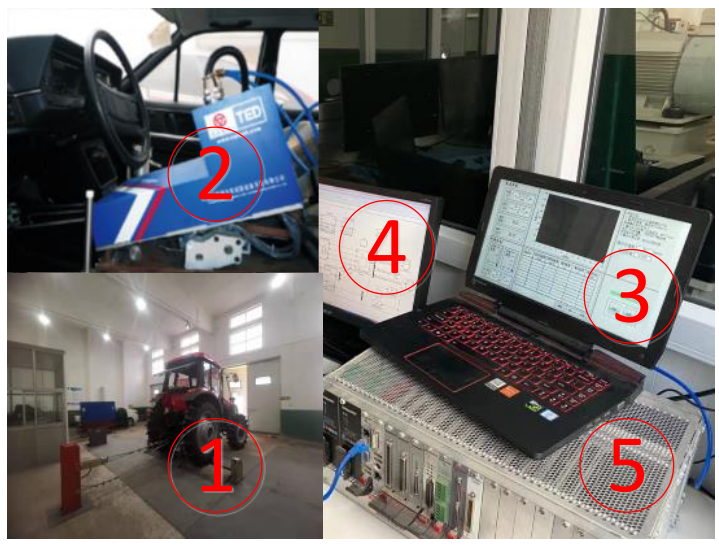

Figure 9 Test site

In Figure 9, 1 is the chassis dynamometer test bench, which loads the actual working condition load for the test tractor through the drum; 2 is the assisted driving device to realize the automatic driving of the tractor; 3 is the test management computer, which monitors various parameters in the test process in real time; 4 is the measurement and control computer, which run the assisted driving device control strategy, and then use the actuator unit in 2 to track the speed of the tractor; 5 is the rapid prototyping controller LINKS-RT simulator of Beijing Lingsi Chuangqi Technology Co., Ltd. Its host computer software is connected with the Simulink software in the measurement and control computer. The information of each sensor is collected in real time and transmitted to the measurement and control computer. According to the load control algorithm of measurement and control computer, it can output the control signal of the chassis dynamometer test bench to load the tractor dynamically.

During the test, the real driver drives the tractor carries on the NEDC condition and ploughing operating condition on the chassis 
dynamometer according to the large-screen operating condition curve prompts firstly. Then the assisted driving device is connected with the tractor fixedly, and the fuzzy PID control strategy proposed in this paper is used to control the assisted driving device to drive the tractor test conditions according to the predetermined program. Figure 10 and Figure 11 show the results of the recording tractor speed following and comparing with the simulation data.

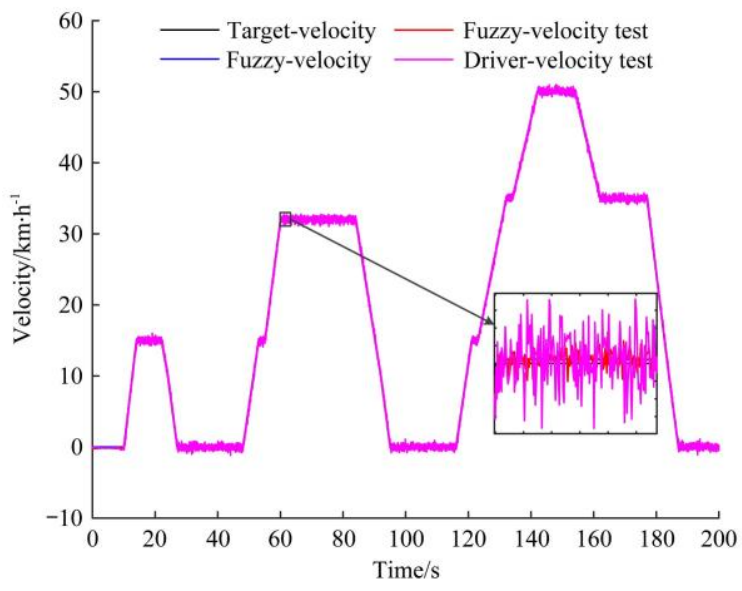

Figure 10 NEDC condition test results

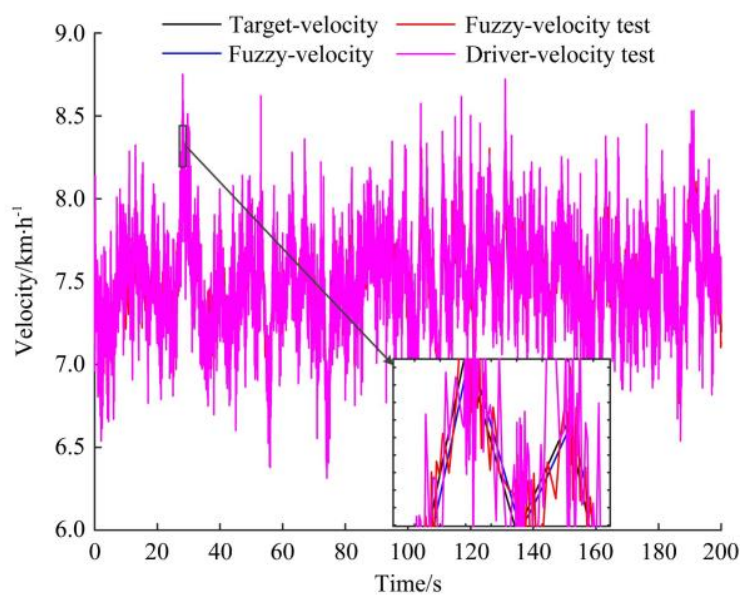

Figure 11 Plowing condition test results

As can be seen from the enlarged parts in Figure 10 and Figure 11 , the test results show that the tractor speed of the real driver driving the tractor and that of assisted driving device using the fuzzy PID control strategy to drive the tractor have a good target speed following effect. Due to the driver's response time, operating level and other factors, the speed of the tractor fluctuates relatively large, and the assisted driving device using the fuzzy PID control strategy will real-time adjust the values of $K_{P}, K_{I}$ and $K_{D}$ according to the input $e(t)$ and $e c(t)$. The adjustment can better follow the working condition curve set by the computer, so the fluctuation range is smaller than that of the driver's operation, which verifies the superiority of the fuzzy PID control strategy for the precise speed control of the assisted driving device.

\section{Conclusions}

Aiming at the assisted driving device of the chassis dynamometer of the automatic transmission tractor, based on the speed control performance requirements and through the analysis of its working principle and working process, a fuzzy PID control strategy is designed based on the traditional PID control, and the following conclusions are mainly obtained:
(1) Through the establishment of the Matlab-Cruise joint simulation platform, it is verified that the fuzzy PID control strategy can more accurately control the tractor speed following situation, and realize the speed following accuracy does not exceed $\pm 0.5 \mathrm{~km} / \mathrm{h}$. Compared with traditional PID control, the response speed and the overall speed following accuracy are greatly improved when the target speed changes suddenly.

(2) Through the actual tractor chassis dynamometer test, it is further verified that the assisted driving device using the fuzzy PID control strategy has a better target speed following effect, and can reduce the fluctuation of the tractor following the speed compared with the driver.

(3) The assisted driving device using the fuzzy PID control strategy can realize the automatic driving of the chassis dynamometer test tractor in the given target test conditions, which can lay the technical foundation for the realization of the unmanned chassis dynamometer test workshop.

\section{Acknowledgements}

This research is supported by the 2016 national key research and development plan (Grant No. 2016YFD070100). The authors thank LetPub (www.letpub.com) for its linguistic assistance during the preparation of this manuscript.

\section{[References]}

[1] The action plan for the development of agricultural machinery and equipment (2016-2025). https://www.miit.gov.cn/zwgk/zcwj/wjfb/zbgy/art/ 2020/art_9eb4d14709f94e6490c6d0463016a723.html. (in Chinese)

[2] Xie B, Wu Z B, Mao E R. Development status and prospect of key technologies of agricultural tractors. Transactions of the CSAM, 2018; 49(8): 1-17. (in Chinese)

[3] Gonzalez D O, Martin-Gorriz B, Berrocal I I, Morales A M, Salcedo G A, Hernandez B M. Development and assessment of a tractor driving simulator with immersive virtual reality for training to avoid occupational hazards. Computers and Electronics in Agriculture, 2017; 143: 111-118.

[4] Okunev A P, Borovkov A I, Karev A S, Lebedev D O, Kubyshkin V I, Nikulina S P, et al. Digital modeling and testing of tractor characteristics. Russian Engineering Research, 2019; 39(6): 453-458.

[5] Sun Y T, Wang Y L, Zhu R F, Geng R G, Zhang J Z, Fan D H, et al Development of test bed of hybrid electric vehicle based on chassis dynamometer. IOP Conference Series: Materials Science and Engineering 2018; 452(4): 042112. doi: 10.1088/1757-899X/452/4/042112

[6] Yan X H, Zhou Z L, Jia F. Compilation and verification of dynamic torque load spectrum of tractor power take-off. Transactions of the CSAE, 2019; 35(19): 74-81. (in Chinese)

[7] Liu W. Simulation and experimental study on modeling load force of chassis dynamometer. MS dissertation. Changchun: Jilin University, 2018; 87p. (in Chinese)

[8] Wang J, Chen G, Wang J W. Driving force simulation and optimization of shift manipulator for vehicle robot driver. Computer Simulation, 2017; 34(5): 347-352. (in Chinese)

[9] Simone C, Angela M. Performance testing of a locomotive engine after treatment pre-prototype in a passenger cars chassis dynamometer laboratory. Transportation Research Procedia, 2016; 14: 605-614.

[10] Yoshihiro N, Yoshizumi K. Determination of nitrous acid emission factors from a gasoline vehicle using a chassis dynamometer combined with incoherent broadband cavity-enhanced absorption spectroscopy. Science of the Total Environment, 2017; 575: 287-293.

[11] Zhang B J, Zhao J Y, Jiao Q H. Vehicle emission durability test bench based on driving robot. Light Vehicle Technology, 2004; Z1: 4-7. (in Chinese)

[12] Xue J L, Zhang W G, Gong Z Y. Robot driver for indoor test of vehicles Automotive Engineering, 2007; 29(10): 893-895. (in Chinese)

[13] Zhang K L, Peng X Y, Hong B, Li Z H, Wang J J, Huang Z Y, et al Design of vehicle robot driver based on the real-time Ethernet EtherCAT. Small Internal Combustion Engine and Vehicle Technology, 2016; 45(5): 57-60. (in Chinese) 
[14] Nikolaus E R, Christian H M, Igor Š, Stefan J, Gorazd K. Automated vehicle drive away with a manual dry clutch on chassis dynamometers: Efficient identification and decoupling control. ISA Transactions, 2020; 98: $237-250$.

[15] Wu X, Zhang Y, Zou T, Zhao L, Lou P H, Yin Z Y. Coordinated path tracking of two vision-guided tractors for heavy-duty robotic vehicles. Robotics and Computer Integrated Manufacturing, 2018; 53: 93-107.

[16] Dam H P, Pongsathorn R, Masao N. Study on driver model for hybrid truck based on driving simulator experimental results. IATSS Research, 2018; 42(1): 18-23.

[17] Butzke J, Daniilidis K, Kushleyev A, Lee D D, Likhachev M, Phillips C, et al. The University of Pennsylvania MAGIC 2010 multi-robot unmanned vehicle system. Journal of Field Robotics, 2012; 29(5): 745-761.

[18] Chen H, Lu W, Zhao X L, Wang L, Zhang Y N, He X H. The fuzzy-adaptive PID control based on the force feedback ofthe tractor robot driver's gear shift mechanical arm. Journal of Nanjing Agricultural University, 2016; 39(1): 166-174. (in Chinese)
[19] Lu W, Chen H, Wang L, Zhao X L, Zhang Y N. Motion analysis of tractor robot driver's gear shift mechanical Arm. Transactions of the CSAM, 2016; 47(1): 37-44. (in Chinese)

[20] Lu W, Chen H, Wang J P, Wang L, Qiu W, Deng Y M. Research on human-computer cooperation method based on tractor driving robot. Journal of Nanjing University of Information Technology (Natural Science Edition), 2019; 11(2): 165-172. (in Chinese)

[21] Li G Y, Yang L J. Neural fuzzy predictive control and its MATLAB implementation. Electronic Industry Press, 2016. (in Chinese)

[22] Yan X H, Xu L Y, Wang Y. The loading control strategy of the mobile dynamometer vehicle based on neural network PID, Mathematical Problems in Engineering, 2017; 2017: 5658983. doi: $10.1155 / 2017 / 5658983$

[23] Zhao Y, Xie J F, Shi J W, Li H D. Energy management strategy of FCHV considering fuel cell durability. Modern Manufacturing Engineering, 2020; 4: 70-76, 158. (in Chinese) 